\title{
Tocoferois do músculo dorsal e cavidade ocular do matrinxã (Brycon cephalus) proveniente da Bacia Amazônica em diferentes épocas sazonais
}

\author{
Tocopherol at the dorsal muscle and orbital cavity of the matrinxã fish (Brycon cephalus) from the Brazilian \\ Amazonian Area captured in different seasons
}

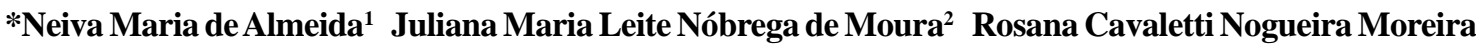 \\ Maria Regina Bueno Franco ${ }^{4}$
}

\section{RESUMO}

Este trabalho teve como objetivo determinar o teor de tocoferois no músculo e cavidade ocular do matrinxã (Brycon cephalus), capturados na Amazônia Central - Brasil, no período da cheia e seca. A coleta dos peixes foi realizada em diferentes épocas sazonais, constituindo-se de três lotes com cinco exemplares. As análises seguiram a metodologia da AOCS Ce 8-89 (1996) em cromatógrafo HPLC PERKIN ELMER - Bomba isocrática LC 250 acoplado a detector de fluorescência (SHIMADZU - RF-10AxL). O $\alpha$-tocoferol foi predominante nas diferentes sazonalidades. No músculo do peixe capturado na época da cheia e seca, o teor de tocoferois variou de 0,04 a $0,43 \mathrm{mg} 100 \mathrm{~g}^{-1}$ e 0,06 a $8,23 \mathrm{mg} 100 \mathrm{~g}^{-1}$, respectivamente. $O$ teor de tocoferois na cavidade ocular, na época da cheia e seca, variou de 0,02 a 0,09mg $100 \mathrm{~g}^{-1}$ e 0,03 a $0,42 \mathrm{mg} 100 \mathrm{~g}^{-1}$, respectivamente.

Palavras-chave: antioxidante, Brycon cephalus, CLAE, matrinxã, tocoferois.

\section{ABSTRACT}

This research aimed to determine the content of different tocopherol levels in muscle and ocular cavity of matrinxã fishes captured in the Central Amazon Region - Brazil. For the antioxidants determination, three batches, each consisting of 5 fish, during two different seasons. The analyses were performed according to the AOCS Ce 8-89 (1993) methodology in chromatography HPLC PERKIN ELMER Isocratic LC 250 pump couple to fluorescence detector (SHIMADZU - RF - 10AxL). The $\alpha$-tocopherol was predominant in the different seasons. The tocopherol content ranged from
0.43 to $0.04 \mathrm{mg} 100^{-1}$ and from 8.2 to $0.06 \mathrm{mg} 100 \mathrm{~g}^{-1}$ in the muscle of matrinxã captured in the flood ad dry season, respectively. The tocopherol content in the adipose tissue of the orbital cavity of matrinxã captured in the flood ad dry season

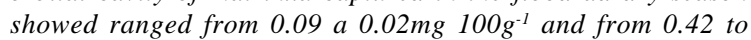
$0.03 \mathrm{mg} 100 \mathrm{~g}^{-1}$, respectively.

Key words: antioxidant, Brycon cephalus, HPLC, matrinxã, tocopherol.

\section{INTRODUÇÃO}

A pesca no Brasil ainda é uma atividade extrativista. Atualmente, a região Norte apresenta a maior produção em peixes e crustáceos de água doce do Brasil, com uma produção total de 225.911 toneladas $\mathrm{ano}^{-1}$. O Estado do Amazonas apresentou em 2003, 28\% do total produzido no Brasil da produção extrativista continental (MMA/ IBAMA/ CEPENE, 2003); entretanto, somente 20 espécies possuem importância comercial no Estado do Amazonas. Em 1998, o total desembarcado concentrou-se principalmente em cinco espécies, entre elas, o matrinxã (Brycon cephalus) (MMA/ IBAMA/ CEPENE/ 2000).

O matrinxã é nativo da bacia Amazônica e pertence ao gênero Brycon, da família Characidae, conhecida como a maior família neotropical de peixes

'Departamento Ciência de Alimentos, Faculdade de Engenharia de Alimentos (FEA), CP 6121, 13081-970, Campinas-SP. Brasil. E-mail: neivaa@yahoo.com

${ }^{2}$ Departamento Tecnologia de Alimentos, FEA, CP 6121, 13081-970, Campinas-SP. Brasil. E-mail: jumanobrega@yahoo.com.br ${ }^{3}$ Departamento Tecnologia de Alimentos, FEA, CP 6121, 13081-970, Campinas-SP. Brasil. E-mail: nogueira@fea.unicamp.br ${ }^{4}$ Departamento Ciência de Alimentos, FEA, CP 6121, 13081-970, Campinas-SP. Brasil. E-mail: franco@fea.unicamp.br. *Autor para correspondência. 
de água doce. Possui excelente aceitação por parte dos consumidores, sendo considerado um peixe de primeira categoria, de acordo com a classificação utilizada no comercio local (FALABELA, 1994). Alcança porte máximo em torno de 3 a $4 \mathrm{~kg}$ de peso e atinge maturação sexual com três anos de idade. É uma espécie migratória, ou de piracema, e sua reprodução em ambiente natural ocorre no início do período da enchente, entre dezembro e fevereiro (ZANIBONI et al., 1988; ZANIBONI \& REZENDE, 1988). Possui hábito alimentar onívoro, alimentando-se na natureza basicamente de sementes e frutos na época da cheia e de insetos, pequenos peixes, moluscos e crustáceos na época da seca(GOULDING, 1980).

O termo vitamina E é considerado como um nome genérico descrevendo as bioatividades de derivados de tocoferois e tocotrienois; vitaminas lipossolúveis que possuem alto poder antioxidante. Os quatro isômeros dos tocotrienois $(\alpha-\mathrm{T} 3, \beta-\mathrm{T} 3, \gamma-\mathrm{T} 3$ e $\delta$ T3) são estruturalmente relacionados aos seus correspondentes homólogos dos tocoferois $(\alpha-\mathrm{T}, \beta-\mathrm{T}$, $\gamma$-T e $\delta$-T), mas diferem nas suas cadeias laterais no qual os isômeros contêm três duplas ligações. A atividade biológica da vitamina $\mathrm{E}$ tem sido associada à sua capacidade antioxidante, especificamente contra a peroxidação lipídica em membranas biológicas. $\mathrm{O}$ isômero $\alpha$-tocoferol apresenta a maior atividade biológica dentro da classe dos tocoferois. (THERIAULT et al., 1999).

Em geral, a composição lipídica do pescado é variável e, depende da época do ano, do tipo e quantidade de alimento disponível, ou seja, da qualidade da dieta consumida, do estágio de maturação sexual, entre outros fatores (JUNK, 1984). O teor de $\alpha$ tocoferol em peixes é determinado por vários fatores e varia de acordo com o teor lipídico, espécie, tamanho, idade, bem como as condições de cultivo (RUFF et al., 2002).

Este trabalho teve como objetivo determinar o teor total de tocoferois no músculo dorsal e no tecido adiposo da cavidade ocular do matrinxã capturado na Amazônia Central, em diferentes épocas sazonais, buscando identificar o melhor tecido como fonte de vitamina E.

\section{MATERIAL E MÉTODOS}

Os peixes foram capturados na Amazônia Central em três lotes, de três barcos distintos, no Porto de Manaus (Brasil), durante o período da cheia (janeiro a julho) e o período da seca (julho a dezembro). Cada lote foi constituído de cinco peixes.

Para cada exemplar, aferiu-se o peso e comprimento total, tendo sido extraídos o músculo dorsal e o tecido adiposo da cavidade ocular que, após trituração, foram submetidos à liofilização, estocados a $-18^{\circ} \mathrm{C}$ sob atmosfera de $\mathrm{N}_{2}$ e transportados para o Laboratório de Óleos e Gorduras, Faculdade de Engenharia de Alimentos, Universidade Estadual de Campinas, para realização de análises de tocoferois. Cada lote foi constituído em uma amostra, tendo sido analisada em duplicata. A determinação de umidade foi realizada, através do processo de liofilização, nos músculos dorsais e tecido adiposo da cavidade ocular, de acordo com PITOMBO (1989). Para a extração dos lipídios totais foi utilizado o método proposto por BLIGH \& DYER (1959). A determinação de tocoferois foi realizada segundo metodologia da AOCS Ce 8-89 (1996) em cromatógrafo HPLC PERKIN ELMER Bomba isocrática LC 250 acoplado a detector de fluorescência (SHIMADZU - RF-10AxL) nas seguintes condições: coluna LiChrosorb Si60 $(5 \mu \mathrm{m})$ de 0,25m x $4 \mathrm{~mm}$, solvente: hexano/isopropanol (99:1), vazão 1,1mL $\mathrm{min}^{-1}$. Os dados foram avaliados pelo teste de variância ANOVA e pelo teste de comparações múltiplas de Tukey, em nível de 5\% de probabilidade, utilizando o software SAS for Windows (1996).

\section{RESULTADOS E DISCUSSÃO}

A tabela 1 mostra os resultados dos teores de umidade e lipídios totais no músculo, além do comprimento e peso dos exemplares de matrinxã. Os resultados são as médias finais dos três lotes relativos aos exemplares capturados na Amazônia Central nos dois períodos sazonais.

De acordo com os teores médios de lipídios totais mostrados na tabela 1 , o peixe capturado no período da cheia pode ser considerado como altamente gordo e o capturado no período da seca medianamente gordo, segundo a classificação de ACKMAN (1989). O teor de gordura do matrinxã capturado na cheia e na seca está em concordância com os valores encontrados por ROCHA et al., (1982) e MAIA et al., (1998), avaliados nos mesmos períodos de captura.

Tabela 1 - Teores de lipídios totais (\%), umidade (\%) e valores de comprimento $(\mathrm{cm})$ e peso $(\mathrm{kg})$ do matrinxã em diferentes situações de captura.

\begin{tabular}{lcccc}
\hline $\begin{array}{c}\text { Época } \\
\text { Sazonal }\end{array}$ & $\begin{array}{c}\text { Lipídios } \\
\text { totais }\end{array}$ & Umidade & Comprimento & Peso \\
\hline Cheia & $9,63 \pm 0,52$ & $71,02 \pm 2,32$ & $32,41 \pm 3,11$ & $0,87 \pm 0,20$ \\
Seca & $4,55 \pm 0,41$ & $72,03 \pm 3,00$ & $36,22 \pm 0,23$ & $1,18 \pm 0,60$ \\
\hline
\end{tabular}

Cada valor é a média das duplicadas, de três lotes, com a respectiva estimativa dos desvios padrão. 
Dentre o teor de tocoferois totais, o $\alpha$ tocoferol foi predominante no músculo, na época de cheia e seca, compreendendo $87,92 \%$ dos tocoferois presentes, e no tecido adiposo da cavidade ocular, na época da seca (Tabela 2). O músculo de matrinxã, capturado no período da seca, apresentou o maior valor de $\alpha$-tocoferol, o que, devido a sua maior atividade antioxidante, confere maior proteção oxidativa aos ácidos graxos insaturados e, em alta concentração, inibe os hidroperóxidos (FRANKEL, 1996). Devido ao considerável teor de EPA $\left(8,14 \mathrm{mg} 100 \mathrm{~g}^{-1}\right)$ e DHA

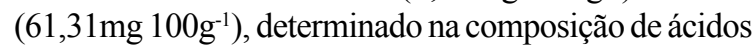
graxos do músculo do matrinxã capturado na época da seca, os quais são bastante susceptíveis à oxidação, o alto teor de $\alpha$-tocoferol encontrado no músculo confere uma melhor estabilidade oxidativa aos mesmos (ALMEIDA, 2004). A maior retenção de $\alpha$-tocoferol no músculo de Atlantic salmon (Salmo salar, L.), em relação aos demais isômeros de tocoferois, também foi verificada por HAMRE \& LIE (1997).

As razões para o maior acúmulo de $\alpha$ tocoferol em tecidos animais constituem-se, atualmente, assunto de investigação. Baseando-se nas pesquisas atuais, há um consenso entre cientistas de que a preferência de acumulação de $\alpha$-tocoferol ocorre na maior parte no fígado onde proteína de transferência $(\alpha$-TTP) foi identificada nos ratos (PACKER et al., 2001). Verifica-se que a $\alpha$-TTP apresenta elevada afinidade pelo $\alpha$-tocoferol, resultando na incorporação preferencial desta forma isomérica nas lipoproteínas, que as transportam aos demais tecidos. Segundo NG et al. (2004), a possível existência da $\alpha$-TTP no fígado de African catfish (Clarias gariepinus), embora a isolação de tal proteína em peixes ainda não tenha sido relatada, constitui-se na provável explicação para o maior acúmulo de $\alpha$-tocoferol no músculo de African catfish. Essa consideração, também poderá cogitada para uma possível explicação do maior teor de $\alpha$ tocoferol encontrado no músculo de matrinxã, tanto no peixe capturado na época da seca, como na época da cheia.

O teor total de tocoferois do músculo e da cavidade ocular, no período de cheia, foi de 0,62 e $0,16 \mathrm{mg}$ $100 \mathrm{~g}^{-1}$, respectivamente, enquanto que, para a estação

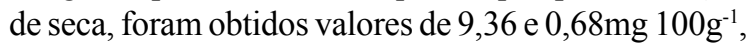
respectivamente. Estes valores evidenciam a influência da alimentação, típica em função da estação de captura, no teor e composição dos tocoferois.

No músculo do peixe capturado na época da cheia e seca, o teor de tocoferois variou de $0,04 \mathrm{a}$

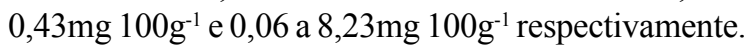
No tecido adiposo da cavidade ocular de matrinxã, capturado na época da cheia e seca, variou de 0,02 a

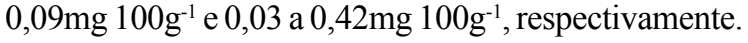
Não se observou diferença significativa $(\mathrm{P}<0,05)$ para o músculo do matrinxã capturado no período da seca em relação aos teores de beta e gama tocoferol. Houve diferença significativa em relação ao tecido adiposo da cavidade ocular do matrinxã capturado na época da seca, para as quatro formas isoméricas de tocoferol. Comparando os dois tecidos, adiposo da cavidade ocular e músculo, houve diferença significativa $(\mathrm{P}<0,05)$ para o teor de alfa, beta e gama tocoferol.

Para os peixes capturados no período da cheia, observou-se predominância do $\alpha$-tocoferol, não havendo diferença significativa $(\mathrm{P}<0,05)$ em relação aos teores de beta e delta tocoferol entre os músculos. Não houve diferença significativa $(\mathrm{P}<0,05)$ em relação ao tecido adiposo da cavidade ocular do matrinxã capturado na época da cheia para os teores de alfa, gama e delta tocoferol. Não houve diferença significativa $(\mathrm{P}<0,05)$ entre o músculo e o tecido adiposo da cavidade ocular dos peixes capturados no período da cheia em relação aos teores de beta e gama tocoferol.

Segundo dados apresentados por NG et al. (2004), os teores de alfa, beta e gama tocoferois, 1,0,

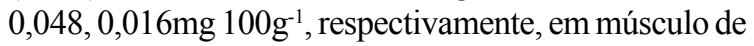

Tabela 2 - Teor de tocoferois (mg/100g) no músculo dorsal e na cavidade ocular do matrinxã capturado na Amazônia Central em duas diferentes épocas sazonais.

Tocoferois

\begin{tabular}{lcccccccc} 
& \multicolumn{2}{c}{ Alfa } & \multicolumn{2}{c}{ Beta } & \multicolumn{2}{c}{ Gama } & \multicolumn{2}{c}{ Delta } \\
\cline { 2 - 8 } $\begin{array}{c}\text { Época } \\
\text { sazonal }\end{array}$ & Músculo & $\begin{array}{c}\text { Cavidade } \\
\text { ocular }\end{array}$ & Músculo & $\begin{array}{c}\text { Cavidade } \\
\text { ocular }\end{array}$ & Músculo & $\begin{array}{c}\text { Cavidade } \\
\text { ocular }\end{array}$ & $\begin{array}{c}\text { Músculo } \\
\text { Cavidade } \\
\text { ocular }\end{array}$ \\
\hline Cheia & $0,43 \pm 0,02 \mathrm{~b}$ & $0,03 \pm 0,02 \mathrm{e}$ & $0,07 \pm 0,09 \mathrm{~d}$ & $0,09 \pm 0,09 \mathrm{~cd}$ & $0,04 \pm 0,03 \mathrm{e}$ & $0,02 \pm 0,01 \mathrm{e}$ & $0,08 \pm 0,09 \mathrm{~d}$ & $0,02 \pm 0,01 \mathrm{e}$ \\
Seca & $8,23 \pm 6,13 \mathrm{a}$ & $0,42 \pm 0,31 \mathrm{~b}$ & $0,55 \pm 0,26 \mathrm{~b}$ & $0,16 \pm 0,14 \mathrm{c}$ & $0,52 \pm 0,50 \mathrm{~b}$ & $0,07 \pm 0,03 \mathrm{~d}$ & $0,06 \pm 0,03 \mathrm{~d}$ & $0,03 \pm 0,04 \mathrm{e}$ \\
\hline
\end{tabular}

Cada valor é a média das duplicadas, de três lotes, com a respectiva estimativa dos desvios padrão. Médias seguidas da mesma letra, não diferem estatisticamente em nível de 5\%. 
African catfish (Clarias gariepinus), totalizando $1,064 \mathrm{mg} 100 \mathrm{~g}^{-1}$, foram bastante inferiores aos encontrados no músculo de matrinxã capturados no período da seca, totalizando $9,36 \mathrm{mg} 100 \mathrm{~g}^{-1}$, dentre os quais o $\alpha$-tocoferol representa $87,92 \%$ dos tocoferois totais. Verifica-se a influência da estação de captura dos peixes no teor de tocoferois, provavelmente devido à mudança da alimentação dos peixes, onde na época da cheia obteve-se como teor total de tocoferois um valor bastante inferior, $0,62 \mathrm{mg}^{100 \mathrm{~g}^{-1}}$, ao valor apresentado na época da cheia, $9,36 \mathrm{mg}^{100 \mathrm{~g}^{-1}}$.

Os teores de $\alpha$-tocoferol encontrados para o matrinxã capturado na época da seca foram superiores aos encontrados para "Pike-perch" (Sander lucioperca), "Trout" (Salmo trutta trutta), "Carp" (Cyprinus carpio), "Sprat" (Sprattus sprattus), "Mackerel" (Trachurus mediterraneus ponticus) (RIBAROVA et al., 2003), porém inferiores aos encontrados por HAMRE \& LIE (1995) para "Atlantic salmon" (Salmon salar), e para o "Atlantic halibut" (Hippoglossus hippoglossus) (RUFF et al., 2002), isso provavelmente é reflexo de diferentes dietas. Teores de $\alpha$-tocoferol em fígados de peixe "Rainbow trout" (Oncorhynchus mykiss), "White sucker" (Catostomus commersoni) e raias Dasyatis brevis e Gymnura marmorata foram superiores aos teores encontrados para o matrinxã (KOPRIVNJAK et al., 1996; NAVARROGARCIA et al., 2004).

\section{CONCLUSÃO}

O teor de tocoferois do músculo e do tecido adiposo da cavidade ocular do matrinxã apresentou correlação com a característica sazonal da Amazônia tendo sido influenciado pela época de captura dos peixes. $\mathrm{O}$ isômero $\alpha$-tocoferol foi predominante no músculo do peixe capturado nos dois períodos estudados. O peixe capturado na época da seca foi considerado melhor pra o consumo, pois apresentou, no músculo, o maior teor do isômero $\alpha$-tocoferol. $\mathrm{O}$ tecido adiposo da cavidade ocular não apresentou quantidade de tocoferois que justifique este ser melhor fonte de antioxidante que o músculo.

\section{AGRADECIMENTOS}

À Coordenação de Aperfeiçoamento de Pessoal de Nível Superior (Capes) e à Fundação de Amparo à Pesquisa do Estado de São Paulo (Fapesp), pela concessão das bolsas de estudos e suporte financeiro.

\section{REFERÊNCIAS}

AMERICAN OIL CHEMIST'S SOCIETY - AOCS. Official and tentative methods. Method AOCS Ce 8-89. Champaign, 1996. p.1-5, 37p.
ACKMAN, R.G. Nutritional composition of fats in seafood. Progress in Food and Nutrition Science, v.13, p.161-241, 1989.

ALMEIDA, N.M. Composição em ácidos graxos e quantificação de EPA e DHA de matrinxã (Brycon cephalus) e tambaqui (Colossoma macropomum) cultivado e capturado na Amazônia Central. 2004. 237f. Tese (Doutorado em Ciência de Alimentos) - Curso de Pós-graduação em Ciência de Alimentos, Universidade Estadual de Campinas.

BLIGH, E.G.; DYER, W.J. A rapid method of total lipid extraction and purification. Canidian Journal Biochemistry Physiology, v.37, p.911-917, 1959.

FALABELA, R.G.P. A pesca no Amazonas: problemas e soluções. 2.ed. Manaus: Imprensa do Estado, 1994. 180p.

FRANKEL, E.N. Antioxidants in lipid foods and their impact on food quality. Food Chemistry, v.57, n.1 p.51-55, 1996.

GOULDING, M. The fishes and the forest, exploration in Amazonian natural history. Berkeley and Los Angeles: University of California, 1980. 280p.

HAMRE, K.; LIE, O. $\alpha$-tocopherol levels in differents organs of Atlantic salmon (Salmo salar L.) - Effect of smoltification, dietary levels of n-3 polyunsaturated fatty acids and vitamin $E$. Comparative Biochemistry Physiology, v.111A, n.4, p.547554, 1995.

HAMRE, K.; LIE, O. Retained levels of dietary alpha, gamma, and delta- tocopherol in tissues and body fluids of Atlantic salmon (Salmo salar L.). Aquaculture Nutrition, v.3, p.99 107, 1997.

JUNK, W.J. Ecology, fisheries and fish culture in Amazonian. In: SIOLI, H. (ED). The Amazon. Dordrecht: Dr. W. Junk Pulb, $1984.763 p$.

KOPRIVNJAK, F.J. et al. Determination of $\alpha-\gamma(+\beta)-$, and $\delta$ tocopherols in a variety of liver tissue by reverse-phase high pressure liquid chromotography. Comparative Biochemistry Physiology. v.113B, n.1, p.143-148, 1996.

MAIA, E.L. et al. Composição de ácidos graxos constituintes de peixes do rio Amazonas. In: CONGRESSO BRASILEIRO DE CIÊNCIA E TECNOLOGIA DE ALIMENTOS, Rio de Janeiro, 1998. Anais... Rio de janeiro, 1998. p.1154-1154.

MMA/ IBAMA/ CEPENE. Estatística da Pesca - Brasil, Grandes Regiões e Unidades da Federação. Tamandaré: Abril, 2003. 96p.

MMA/ IBAMA/ CEPENE. Estatística da Pesca - Brasil, Grandes Regiões e Unidades da Federação. Tamandaré: Abril, 2000. 96p.

NAVARRO-GARCIA, G. et al. Characterization of the lipid composition and natural antioxidants in the liver oil of Dasyatis brevis and Gymnura marmorata rays. Food Chemistry, v.87, p.89-96, 2004.

NG, W.K. et al. Replacement of dietary fish oil with palm fatty acid distillate elevates tocopherol and tocotrienol concentrations and increases oxidative stability in the muscle of African catfish, Clarias gariepinus. Aquaculture, v.233 p.423-437, 2004. 
PACKER, L. et al. Molecular aspects of $\alpha$-tocotrienol antioxidant action and cell signalling. Journal Nutrution, v.131, p.369-373, 2001.

PITOMBO, R.N.M. A liofilização como técnica de conservação de material de pesquisa. Ciência e Cultura, v.41, n.5, p.427$431,1989$.

RIBAROVA, F. et al. $\alpha$-Tocopherol, fatty acids and their correlations in Bulgarian foodstuffs. Journal of Food Composition and Analysis, v.16 p.659-667, 2003

ROCHA, Y.R. et al. Aspectos nutritivos de alguns peixes da Amazônia. Acta Amazônica, v.12 n.4, p.787-794, 1982.

RUFF, N. et al. Fillet shelf-life of Atlantic halibut (Hippoglossus hippoglossus L. Fed elevated levels of $\alpha$-tocopheryl acetate. Aquaculture Research, v.33, p.1059-1071, 2002.
SAS Statistical Analytical System, SAS Institute INC. SAS Campus drive. Cary, Caroline, USA, 1996. Version 6.0.

THERIAULT, A. et al. Tocotrienol: a reviw of its therapeutic potential. Clinical Biochemistry, v.32, n.5, p.309-319, 1999.

ZANIBONI-FILHO, E. et al. Caracterização morfológica do matrinxã, Brycon cephalus (GÜNTHER, 1869) (TELEOSTEI: CHARACIDAE). Revista Brasileira Biologia, v.48, n.1, p.41-50, 1988 .

ZANIBONI FILHO, E.; REZENDE, E. Anatomia de gônadas, escala de maturidade e tipo de desova do matrinxã, Brycon cephalus (GÜNTHER, 1869) (Teleostei: Characidae). Revista Brasileira Biologia, v.48, n.4, p.833-844, 1988. 